\title{
Computed Tomography-Guided Optical Sensor-Guided Percutaneous Needle Biopsy
}

National Cancer Institute

\section{Source}

National Cancer Institute. Computed Tomography-Guided Optical Sensor-Guided

Percutaneous Needle Biopsy. NCI Thesaurus. Code C116444.

The use of CT imaging to guide the placement of a needle being used to obtain a tissue sample. 